\title{
Ceratectomia fototerapêutica (PTK) e ceratopatia bolhosa: relato de caso
}

\author{
Phototherapeutickeratectomy(PTK)and bullouskeratopathy:case report
}

\author{
Wilson Nahmatallah Obeid ${ }^{1}$ \\ Karina de Paula Richinho ${ }^{2}$ \\ Alex Piai Osores ${ }^{3}$ \\ Marco Antônio de Campos Machado ${ }^{4}$ \\ Rita de Cássia Lima Obeid5 \\ Luiz Antônio Vieira ${ }^{6}$
}

\begin{tabular}{|c|}
\hline RESUMO \\
\hline O objetivo é avaliar os efeitos da ceratectomia fototerapêutica (PTK) em \\
pacientes com ceratopatia bolhosa. Foi realizada ceratectomia fototera- \\
pêutica em paciente pseudofácico com descompensação corneana pós- \\
facectomia, com excimer laser Nidek EC 5000, após debridamento epitelial \\
manual. O paciente apresentou melhora da dor a partir do décimo quinto \\
dia após a aplicação do laser e durante os oito meses de seguimento. Não \\
houve melhora da acuidade visual. A realização de ceratectomia fototera- \\
pêutica deve ser considerada uma alternativa a mais no tratamento da dor \\
em ceratopatia bolhosa de pseudofácicos. \\
\hline
\end{tabular}

Descritores: Ceratoplastia penetrante; Pseudofacia; Doenças da córnea/cirurgia; Ceratectomia fotorrefrativa por excimer laser; Relatos de casos [tipo de publicação]

\section{INTRODUÇ̃̃O}

A ceratopatia bolhosa tem como principais causas a distrofia de Fuchs, o trauma perfurante e os procedimentos cirúrgicos, principalmente a facectomia com ou sem implante de lente intra-ocular ${ }^{(1)}$. Apesar das complicações da facectomia ocorrerem em baixa incidência, podem afetar um grande número de pacientes, por ser um procedimento muito comum ${ }^{(2)}$. O edema corneano como resultado de facectomia tem se tornado a maior causa de baixa de acuidade visual e principal indicação de transplante de córnea, quando o desconforto e a diminuição da visão tornam-se intratáveis com medicação ${ }^{(3)}$.

Os principais sintomas da ceratopatia bolhosa são baixa acuidade visual, dor, lacrimejamento, fotofobia e hiperemia ocular. Os sinais biomicroscópicos são bolhas epiteliais e subepiteliais, neovascularização corneana e guttata no endotélio ${ }^{(4)}$.

A histopatologia da ceratopatia bolhosa no afácico e pseudofácico tem sido geralmente inespecífica. O primeiro fator é a diminuição do número de células endoteliais com edema estromal associado. Há um espessamento da camada de colágeno posterior da membrana de Descemet e uma diminuição dos ceratócitos estromais $^{(5)}$. Ocorre também proliferação de fibrose subepitelial e retrocorneana. Células inflamatórias e macrófagos são vistos no estroma corneano profundo e depositados como precipitados ceráticos no endotélio ${ }^{(6)}$.

A perda de função endotelial é o processo final do desenvolvimento do edema corneano no afácico e pseudofácico, embora as causas potenciais de dano endotelial sejam muitas, como toque endotelial contínuo ou intermitente de vítreo ou lente intra-ocular deslocada ${ }^{(4)}$.

A perda endotelial após extração da catarata intracapsular sem colocação de lente intra-ocular é em torno de $12 \%^{(7-8)}$. Alguns autores encontraram de 3,5\% a $10 \%$ de perda endotelial em três meses após facoemulsificação com colocação de lente intra-ocular de câmara posterior ${ }^{(9-11)}$. 
Outras causas de ceratopatia bolhosa no afácico e pseudofácico são edema endotelial preexistente com baixa contagem de células endoteliais, distrofia de Fuchs ou guttata e fatores intra-operatórios, como excesso de soluções de irrigação, manipulação excessiva, perda vítrea, toxicidade por drogas e descolamento da membrana de Descemet ${ }^{(3)}$.

O tratamento é feito com colírios tópicos, tais como lubrificantes, corticosteróides, antibióticos e agentes hiperosmóticos. O tratamento de escolha para a ceratopatia bolhosa é o transplante de córnea. Nos casos em que ele é contra-indicado, pode-se optar por punctura ${ }^{(12)}$, lente de contato terapêuti$\mathrm{ca}$, recobrimento conjuntival ou membrana amniótica ${ }^{(13)}$.

A ceratectomia fototerapêutica (PTK) é utilizada para tratar lesões corneanas anteriores como opacidade de córnea e distrofias. Com o excimer laser, a remoção de tecidos é rápida e precisa. Alguns autores relataram a utilização do PTK para tratamento da dor em pacientes com ceratopatia bolhosa, apresentando bons resultados ${ }^{(14-16)}$.

Foi realizado PTK em um caso de paciente pseudofácico com ceratopatia bolhosa, com queixa de dor e baixa acuidade visual.

\section{RELATO DE CASO}

Paciente L.T.V., sexo feminino, 85 anos.

História da moléstia atual - Paciente chegou ao Instituto CEMA há 1 ano e meio, com queixas de baixa visão e dor em olho direito há 6 meses e exacerbação da mesma nos últimos 3 meses. Relatava cirurgia de facectomia com implante de lente intra-ocular no olho direito há 1 ano. Fez uso de colírios lubrificantes e agentes hiperosmóticos tópicos por 6 meses, sem melhora. Foi inscrita no banco de olhos para transplante de córnea no olho direito.

Antecedentes pessoais - nada digno de nota e Antecedentes familiares - nada digno de nota.

Acuidade visual (cc) - OD: conta-dedos a 1 metro e OE: 0,8.

Biomicroscopia - OD: conjuntiva com hiperemia leve; bolhas epiteliais grandes e pequenas por quase toda a superfície corneana, com edema 3+/4+, dobras de Descemet e corando em ponteados à fluoresceína; pseudofacia e OE: córnea sem alteração; cristalino com catarata incipiente.

Tonometria - OD: $12 \mathrm{mmHg}$ e OE: $10 \mathrm{mmHg}$.

Fundo de olho - OD: prejudicado por opacidade de meios e OE: normal.

Ultra-sonografia - AO: normal.

Paquimetria - OD: $750 \mu \mathrm{m}$ e OE: $480 \mu \mathrm{m}$.

Microscopia especular - OD: difícil contagem e OE: 2.300 células (Figura 1).

Foi realizada no olho direito ceratectomia fototerapêutica (PTK) com excimer laser Nidek EC 5000 após debridamento epitelial manual, com diâmetro de ablação de $7 \mathrm{~mm}$ e profundidade de $175 \mu \mathrm{m}$ (23\% da espessura corneana), sob anestesia tópica com cloridrato de proximetacaína $0,5 \%$. No pós-operatório, foram utilizados colírios de ofloxacina $0,3 \%$ e dexameta- sona $0,05 \%$ quatro vezes ao dia por quatro semanas, lente de contato terapêutica e colírios lubrificantes durante todo o seguimento (oito meses). A lente de contato terapêutica foi trocada a cada 10 dias no pós-operatório, tendo sido mantida por 3 meses. Após 1 mês de cirurgia foi retirada a dexametasona, sendo mantidos a ofloxacino e o lubrificante.

A paciente não referiu dor logo após o procedimento nem ao longo dos 8 meses de seguimento.

Biomicroscopia - OD: presença de microbolhas no epitélio corneano na região da área ablada, corando em ponteados à fluoresceína, e a córnea periférica manteve-se com bolhas subepiteliais, edema estromal $3+/ 4+$, hiperemia conjuntival $2+/ 4+$ (Figura 2).

Após 3 meses de evolução houve persistência das microbolhas epiteliais na área ablada e remissão das bolhas subepiteliais periféricas.

Atualmente, 8 meses após o PTK, observamos persistência das microbolhas centrais, onde foi realizado o tratamento, e discretas bolhas periféricas (Figura 3). A paciente não mais se queixou de dor e não houve alteração da sua acuidade visual.

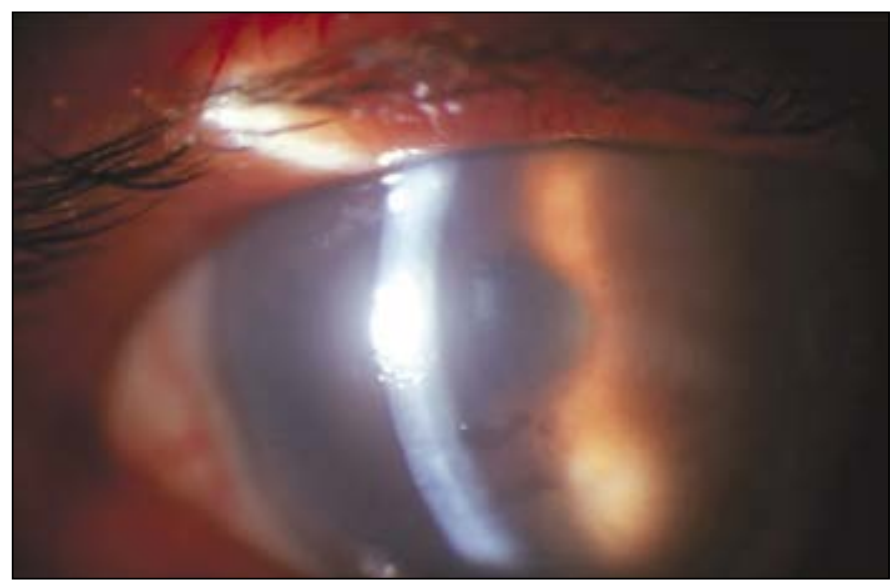

Figura 1 - Pré-operatório: Bolhas subepiteliais no olho direito

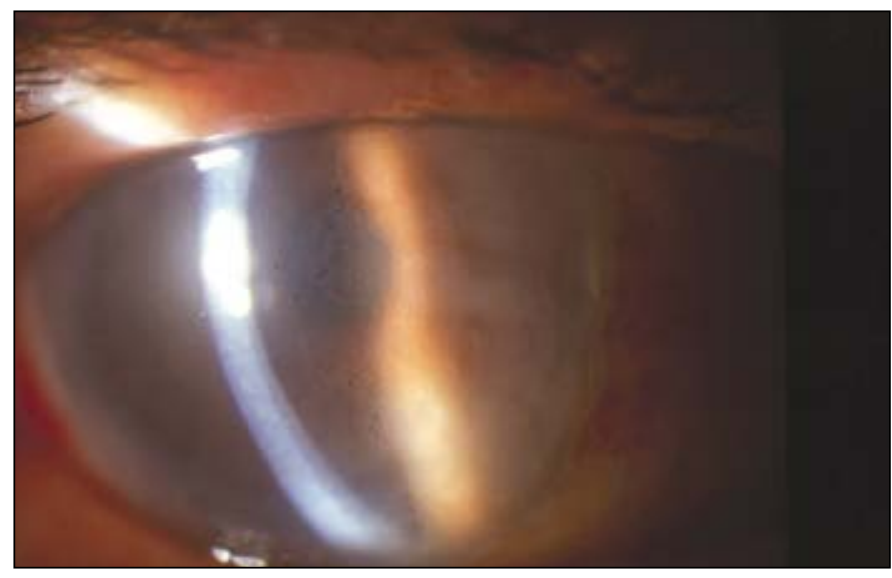

Figura 2 - Evolução de 1 mês após PTK: Microbolhas epiteliais 


\section{DISCUSSÃO}

O plexo nervoso sensorial da córnea, derivado do ramo nasociliar da divisão oftálmica do nervo trigêmio localiza-se no estroma, na região subepitelial. A ablação desse plexo nervoso poderia reduzir a sensibilidade corneana, explicando a melhora da dor após tratamento com PTK. A adesão normal entre as células basais epiteliais, sua membrana basal e o estroma corneano se deve à presença de hemidesmossomos, lâmina basal e fibrilas ancoradoras. Após o PTK, há um aumento no número de hemidesmossomos ${ }^{(17)}$, havendo uma melhor adesão com a formação de uma superfície mais regular. Outro processo que pode estar envolvido neste tratamento é

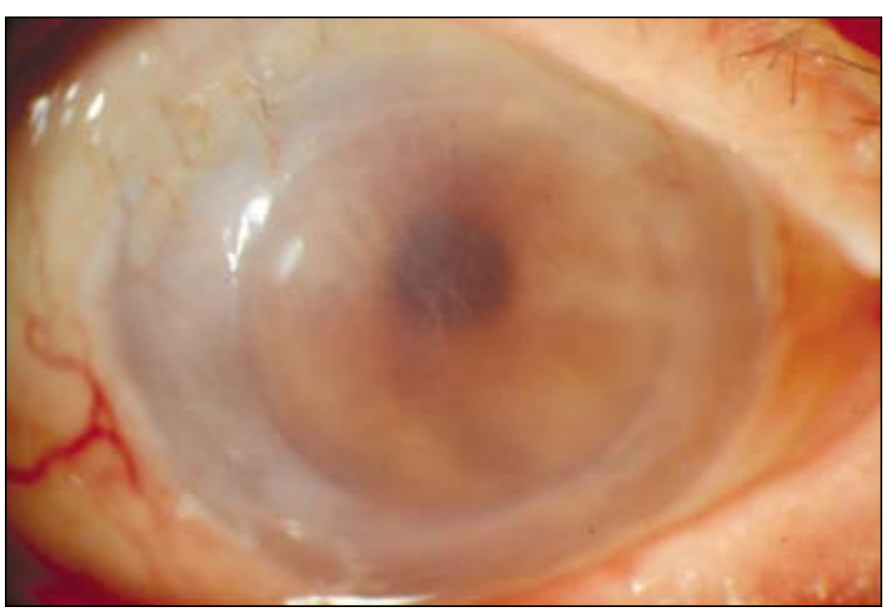

Figura 3 - Evolução de 8 meses após PTK: Microbolhas, discreto edema e dobras de Descemet o aumento da expressão de proteínas extracelulares (colágeno tipo IV, fibronectina e laminina), que são importantes para a adesão epitelial ao estroma subjacente ${ }^{(18)}$. Além disso, a redução da espessura da córnea após o PTK poderia reduzir o edema epitelial por reduzir a carga osmótica do estroma, aumentando a eficácia de "desidratação" da córnea pelo endotélio remanescente ${ }^{(1)}$.

A remoção do epitélio antes do tratamento com laser é necessária para se tratar a membrana basal e fortalecer a adesão entre ela e as células epiteliais. Na ceratopatia bolhosa há uma marcada fibrose subepitelial, que é totalmente removida pelo PTK, o que seria uma razão para a melhora da acuidade visual após o laser ${ }^{(19)}$. Em nosso estudo não houve alteração da mesma.

Alguns autores descreveram o tratamento da dor na ceratopatia bolhosa com PTK em dezessete olhos, obtendo alívio da mesma poucas semanas após o procedimento. Pacientes pseudofácicos com ceratopatia bolhosa foram tratados com PTK, havendo remissão da dor e leve melhora na acuidade visual durante um período de seguimento de dezoito meses ${ }^{(15,19)}$. Estes resultados são semelhantes aos descritos por outros pesquisadores, onde foram tratados 22 olhos com melhora da dor em todos os pacientes ${ }^{(20)}$. Em outra pesquisa foram analisados os resultados de PTK com diferentes profundidades de ablação corneana, obtendo mais sucesso na melhora da dor com ablação profunda ( $25 \%$ da espessura corneana). Em um estudo com PTK e lente de contato terapêutica por três meses no pósoperatório não houve recorrência das bolhas ou da dor, talvez por esse período coincidir com a formação do complexo de adesão entre o epitélio e o estroma corneano ${ }^{(16)}$. Estudos em animais mostraram que este complexo é restaurado em 6 a 8 semanas após uma ablação, portanto, a aplicação de lente de

\begin{tabular}{|c|c|c|c|c|c|c|c|c|c|c|}
\hline \multicolumn{11}{|c|}{ Anexo 1. Demonstra os artigos realizados na literatura e o caso descrito } \\
\hline Artigos & $\begin{array}{c}\mathbf{N} \\
\text { olhos }\end{array}$ & Laser & $\begin{array}{l}\text { Paqui } \\
\text { pré }\end{array}$ & $\begin{array}{l}\text { Prof. } \\
\text { trat. }\end{array}$ & $\begin{array}{l}\text { Paqui } \\
\text { pós }\end{array}$ & $\begin{array}{l}\text { Tempo } \\
\text { epitel. }\end{array}$ & Compl. & Retrat. & Follow-up & $\begin{array}{l}\text { Alívio } \\
\text { sint. }\end{array}$ \\
\hline $\begin{array}{l}\text { Br J Ophthalmol } \\
1995^{(19)}\end{array}$ & 13 & MEL 60 & & & & & & 5 & $24 \mathrm{~m}$. & $100 \%$ \\
\hline $\begin{array}{l}\text { Klin Oczna } \\
1995^{(20)}\end{array}$ & 14 & & & & & & & & $12 \mathrm{~m}$. & $100 \%$ \\
\hline $\begin{array}{l}\text { J Refract Surg } \\
1996^{(14)}\end{array}$ & 17 & MEL 60 & & & & & & 5 & $32 \mathrm{~m}$. & $100 \%$ \\
\hline $\begin{array}{l}\text { Br J Ophthalmol } \\
2001^{(16)}\end{array}$ & 8 & $\begin{array}{c}\text { Summit } \\
\text { Apex Plus }\end{array}$ & & $\begin{array}{l}75 \mu \mathrm{m} \\
\text { todos }\end{array}$ & & 3 sem. & & & $15 \mathrm{~m}$. & $100 \%$ \\
\hline \multirow[t]{2}{*}{$\begin{array}{l}\mathrm{Br} \mathrm{J} \text { Ophthalmol } \\
2001^{(1)}\end{array}$} & & $\begin{array}{l}\text { Nidek } \\
\text { EC } 5000\end{array}$ & & $25 \mu \mathrm{m}$ & & & $\begin{array}{l}\text {-Defeito } \\
\text { epitelial }\end{array}$ & & $13 \mathrm{~m}$. & $70 \%$ \\
\hline & $\begin{array}{c}2^{\circ} \mathrm{G}-5 \\
3^{\circ} \mathrm{G}-24\end{array}$ & & $\begin{array}{l}\text { Média } \\
762 \mu \mathrm{m}\end{array}$ & $\begin{array}{c}50 \text { a } 100 \mu \mathrm{m} \\
25 \% \text { espes. } \\
\text { central }\end{array}$ & & & $\begin{array}{l}\text {-Ceratite } \\
\text { bacterian } \\
\text {-Uveíte }\end{array}$ & & $\begin{array}{l}13 \mathrm{~m} . \\
18 \mathrm{~m} .\end{array}$ & $\begin{array}{l}40 \% \\
85 \%\end{array}$ \\
\hline $\begin{array}{l}\text { J Refract Surg } \\
2002^{(15)}\end{array}$ & 12 & MEL 60 & $\begin{array}{l}\text { Média } \\
706 \mu \mathrm{m}\end{array}$ & $\begin{array}{l}120 \mu \mathrm{m} \\
\text { todos }\end{array}$ & $495 \mu \mathrm{m}$ & 2 sem. & & & 6 a. & $100 \%$ \\
\hline $\begin{array}{l}\text { Caso } \\
\text { descrito }\end{array}$ & 1 & $\begin{array}{l}\text { Nidek } \\
\text { EC } 5000\end{array}$ & $750 \mu \mathrm{m}$ & $\begin{array}{c}175 \mu \mathrm{m} \\
(23 \%)\end{array}$ & $450 \mu \mathrm{m}$ & 3 sem. & & & $12 \mathrm{~m}$. & $\begin{array}{c}\text { Sem } \\
\text { queixas }\end{array}$ \\
\hline
\end{tabular}


contato terapêutica nesse período pode evitar a recorrência das bolhas, evitando a entrada de fluido entre epitélio e estroma quando o complexo de adesão ainda não se formou ${ }^{(16)}$.

A indicação de PTK em ceratopatias bolhosas, comparativamente a outros procedimentos, apresenta algumas vantagens. Em relação ao tratamento com punctura corneana, o laser é mais seguro por não oferecer risco de perfuração. Quanto à lente de contato terapêutica, o risco iminente de infecção limita o seu uso. A opção de recobrimento conjuntival pode aliviar os sintomas definitivamente, porém pode interferir no prognóstico diante do transplante de córnea, por levar vasos sanguíneos à córnea. O uso da membrana amniótica para tratamento da ceratopatia bolhosa também foi descrito com sucesso no alívio dos sintomas ${ }^{(21)}$, porém também é um procedimento cirúrgico, e às vezes há dificuldade na obtenção deste tecido. Nem todos os pacientes querem ser submetidos a outro procedimento cirúrgico e nem todos têm condições clínicas para isso. Além disso, muitos pacientes não têm prognóstico visual bom para se inscrever no banco de olhos para transplante de córnea e, quando têm, aguardam na fila com dor. O PTK é uma opção efetiva para esses casos. O transplante pode ser realizado após o laser, porque o mesmo não gera irregularidade do leito receptor nem aumenta a neovascularização ${ }^{(13)}$.

Nosso caso sugere que o PTK pode ser um tratamento efetivo para casos de dor em ceratopatia bolhosa em pacientes que estão no banco de olhos aguardando transplante de córnea e para aqueles com mau prognóstico de visão.

\section{ABSTRACT}

The objective is to evaluate the effects of phototherapeutic keratectomy (PTK) in bullous keratopathy patients. Phototherapeutic keratectomy was performed in a pseudophakic patient with corneal decompensation after lens extraction, with the excimer laser Nidek EC 5000 after manual corneal epithelial debridement. There was no pain after fifteen days the laser applicattion and during the eight months of follow-up. Visual acuity was unchanged. The phototherapeutic keratectomy excimer laser must be considered one more alternative for pain treatment in bullous keratopathy of pseudophakic patients.

Keywords: Keratoplasty, penetrating; Pseudophakia; Corneal diseases/surgery; Keratectomy, photorefractive, excimer laser; Case reports [publication type]

\section{REFERÊNCIAS}

1. Maini R, Sullivan L, Snibson GR, Taylor HR, Loughnan MS. A comparison of different depth ablations in the treatment of painful bullous keratopathy with phototherapeutic keratectomy. Br J Ophthalmol. 2001;85(8):912-5.

2. Steinberg EP, Javitt JC, Sharkey PD, Zuckerman A, Legro MW, Anderson GF, et al. The content and cost of cataract surgery. Arch Ophthalmol. 1993;111(8):1041-9.

3. Waving GO 3rd. The 50-year epidemic of pseudophakic corneal edema. Arch Ophthalmol. 1989;107(5):657-9.

4. Rheve DJ, Pyges MF. Manual das doenças oculares "Wills Eye Hospital". 3a ed. Rio de Janeiro: Cultura Médica; 2002.

5. Liu GJ, Okisaka S, Mizukawa A, Momose A. Histopathological study of pseudophakic bullous keratopathy developing after anterior chamber or iris supported intra-ocular lens implantation. Jpn J Ophthalmol. 1993;37(4):414-25.

6. Wolter JR. [Pathology of the corneal endothelium in pseudophakic keratophathy]. Fortschr Ophthalmol. 1987;84(2):109-14. German.

7. Bourne WM, Kaufman HE. Endothelial damage associated with intra-ocular lenses. Am J Ophthalmol. 1976;81(4):482-5.

8. Cheng H, Sturrock GD, Rubinstein B, Bulpitt CJ. Endothelial cell loss and corneal thickness lens implantation intracapsular extraction and iris clip lens implantation: a randomized controlled trial. Br J Ophthalmol. 1977;61(12):785-90.

9. Werblin TP. Long term endothelial cell loss following phacoemulsification model for evaluation endothelial damage after intra-ocular surgery. Refract Corneal Surg. 1993;9(1):29-35.

10. Hayashi K, Nakao F, Hayashi F. Corneal endothelial cell loss after phacoemulsification using nuclear cracking technique. J Cataract Refract Surg. 1994;20(1):44-7.

11. Koch DD, Liu JF, Glasser DB, Merin LM, Haft E. A comparison of corneal endothelial change after use of Healon or Viscoat during phacoemulsification. Am J Ophthalmol. 1993;115(2):188-201.

12. Cormier G, Brunette I, Boisjoly HM, LeFrancois M, Shi ZH, Guertin MC. Anterior stromal punctures for bullous keratophaty. Arch Ophthalmol. 1996;114(6):654-8.

13. Pires RT, Tseng SC, Prabhasawat P, Puangsricharern V, Maskin SL, Kim JC, et al. Amniotic membrane transplanation for symptomatic bullous keratopathy. Arch Ophthalmol. 1999;117(10):1291-7.

14. Thomann U, Niesen U, Schipper I. Successful phototherapeutic keratectomy for recurrent erosions in bullous keratopathy. J Refract Surg. 1996;12(2):S290-2.

15. Rosa N, Cennamo G. Phototherapeutic keratectomy for relief of pain in patients with pseudophakic corneal edema. J Refract Surg. 2002;18(3):276-9.

16. Lin PY, Wu CC, Lee SM. Combined phototherapeutic keratectomy and therapeutic contact lens for recurrent erosions in bullous keratopathy. $\mathrm{Br} \mathrm{J}$ Ophthalmol. 2001;85(8):908-11.

17. Fountain TR, de la Cruz Z, Green WR, Stark WJ, Azar DT. Reassembly of corneal epithelial adhesion structures after excimer laser keratectomy in humans. Arch Ophthalmol. 1994;112(7):967-72.

18. Ohji M, Mandarino L, SundarRaj N, Thoft RA. Corneal epithelial attachment with endogenous laminin and fibronectin. Invest Ophthalmol Vis Sci. 1993;34(8):2487-92.

19. Thomann U, Meier-Gibbons F, Schipper I. Phototherapeutic keratectomy for bullous keratopathy. Br J Ophthalmol. 1995;79(4):335-8.

20. Wojciechowska R, Mrukwa E, Gierek-Ciaciura S. [Treatment of bullous keratopathy with excimer laser.] Klin Oczna. 1995;97(11-12):340-2. Polish.

21. Donato WBC, Santos MS, Santos N, Souza LB, Rigueiro MP, Gomes JAP. Uso de transplante de membrana amniótica no tratamento da ceratopatia bolhosa. Arq Bras Oftalmol. 2003;66(2):121-4.

Nos artigos enviados para publicação, o nome dos autores e suas afiliações devem estar completos. Isso facilitará a indexação e os links com as bases de dados e o CV Lates. 